\title{
DIENES: EXPERTISE E PRODUÇÃO DE SABERES NO BRASIL NA DÉCADA DE 1970
}

\author{
Denise Medina de Almeida França ${ }^{1}$ \\ Elenice de Souza Lodron Zuin²
}

RESUMO: Este texto busca evidenciar o processo de constituição de um expert na formação docente, no caso Zoltán Dienes, durante o Movimento da Matemática Moderna, na sistematização de saberes no ensino primário, mediante análise das propostas de modificações na abordagem da matemática elementar por meio de suas ideias. Hipótese inicial: Dienes produziu saberes para formação docente, com suas propostas pedagógicas em Un Programme de Mathématique pour Le Niveau Élémentaire - traduzido e distribuído no Brasil pelo Grupo de Estudos do Ensino da Matemática, em 1969. A questão norteadora: Dienes pode ser considerado expert em matemática para as séries iniciais? A fundamentação teórica concentra-se em Borer (2009) e Hofstetter et al. (2017), novos aportes teórico-metodológicos sobre os saberes profissionais do professor que ensina matemática, sustentados em sínteses históricas sobre o saber docente, com referências que mobilizam categorias como "saberes a ensinar"/"saberes para ensinar". Os resultados confirmam a hipótese, caracterizando Dienes como expert em educação na objetivação de saberes para a formação docente.

Palavras-chave: Saberes para Ensinar. Formação de Professores. Expertise Profissional. Educação Matemática.

\section{DIENES: THE EXPERTISE AND THE PRODUCTION OF KNOWLEDGE IN BRAZIL IN THE $1970^{s}$}

\begin{abstract}
This paper seeks to highlight the process of constitution of an expert in teacher training, in the Zoltán Dienes case during the Modern Mathematics Movement, for the systematization of knowledge in primary education, by analyzing how modifications were proposed in the approach to elementary mathematical knowledge through their proposals. We start from the hypothesis that these teachers, expert in education, produced knowledge for the training of teachers who teach mathematics in primary, analyzing the pedagogical proposals in Un Programme de Mathématique pour Le Niveau Élémentaire - translated and distributed to Brazilian teachers, by the Study Group of Mathematics Teaching, in
\end{abstract}

1 Doutora em Educação. Docente da Universidade do Estado do Rio De Janeiro (UERJ) - Maracanã. Rio de Janeiro-RJ/Brasil. E-mail: denisemedinafranca@gmail.com

2 Doutora em Educação Matemática. Docente da Pontifícia Universidade Católica (PUC Minas). Belo Horizonte MG/Brasil. E-mail: elenicezuin@gmail.com 
1969. The guiding question of the work is: Zoltán Dienes can be considered expert in mathematics for the initial series? We use the theoretical assumptions of Borer (2009) and Hofstetter et al. (2017), new theoretical-methodological contributions to the research on the professional knowledge of the teacher who teaches mathematics, supported by historical syntheses about teacher knowledge, which announces references that mobilize categories such as "knowledge to teach" and "knowledge to teach" as theoretical basis for the study of the Program. The results confirm the hypothesis and characterize Dienes as an expert in education in objectifying knowledge for teacher education.

Keywords: Knowledge to teach. Teacher Training. Professional Expertise. Mathematics Education.

\section{DIENES: LA EXPERTICIA Y LA PRODUCCIÓN DE SABERES EN BRASIL EN LA DÉCADA DE 1970}

RESUMEN: Este texto busca evidenciar el proceso de constitución de un experto en la formación de profesores, en el caso Zoltán Dienes durante el Movimiento de la Matemática Moderna para la sistematización de saberes en la enseñanza primaria, por medio del análisis de cómo fueron siendo propuestos cambios en el enfoque de saberes matemáticos elementales a través de sus propuestas. Hipótesis inicial: ¿Dienes produjo saber para la formación de los docentes, con sus propuestas pedagógicas en Un Program of Mathématique pour Le Niveau Élémentaire, traducido y distribuido a los profesores brasileños, por el Grupo de Estudios de la Enseñanza de las Matemáticas, en 1969. La cuestión orientadora del trabajo es: ¿Dienes puede ser considerado experto en matemáticas para las series iniciales? La fundamentación teórica se concentra en Borer (2009) y Hofstetter et al. (2017), nuevos aportes teórico-metodológicos sobre los saberes profesionales del profesor que enseña matemáticas, sostenidos en síntesis históricas sobre el saber docente, con referencias que movilizan categorías como "saberes a enseñar"/"saber para enseñar". Los resultados confirman la hipótesis, caracterizando a Dienes como experto en educación en la objetivación de saberes para la formación docente.

Palabras clave: Saberes para enseñar. Formación de profesores. Experiencia Profesional. Educación Matemática.

As décadas de sessenta e setenta do século XX têm determinadas peculiaridades relativas ao ensino da Matemática para o nível de instrução primária no Brasil. A implantação das reformas do sistema de ensino do Estado, no tocante às deliberações da primeira Lei de Diretrizes e Bases da Educação Nacional, Lei 4.024/1961, perpassou diferentes estratégias. Entre elas, destacam-se os cursos de capacitação ofertados pelo Estado e distribuição de publicações dirigidas aos professores, de modo a fazer circular prescrições metodológicas e 
diretrizes para funcionamento das escolas na nova estrutura organizacional da rede oficial de ensino e orientações referentes ao ofício docente. Nesse cenário, a emergência de saberes profissionais se fazia presente.

Igualmente, na década de 1960 e até um pouco antes, em diversos países ocorreu o chamado Movimento da Matemática Moderna (MMM) que se constituiu em um conjunto de ações desenvolvidas em grande parte do mundo, originadas pelo descompasso entre o desenvolvimento da Matemática e o seu ensino dentro das escolas. Ele, de um modo geral, objetivava "modernizar" o ensino e a aprendizagem da Matemática, alterando e atualizando os conteúdos e métodos, incentivando a participação de professores em eventos nos quais se discutia o tema. Dentro desse contexto, a Lei 4024/61 propiciava, aos sistemas de ensino, flexibilidade curricular, criando oportunidades para que fossem absorvidas as ideias do MMM e novas experiências de ensino/aprendizagem.

Em grande medida, nas séries iniciais, currículos e Programas ${ }^{3}$ foram influenciados pelos estudos do educador matemático húngaro Zoltán Pál Dienes (1916-2014)

Dienes, matemático húngaro, nascido em 1916, obtém o título de Doutor em Matemática e Psicologia, pela Universidade de Londres, em 1939. É um dos grandes pioneiros dos estudos alusivos à metodologia para o ensino nas séries iniciais e considerado referência no campo da Educação Matemática, em decorrência de suas teorias sobre a aprendizagem. Seus estudos exploram, principalmente, a construção de conceitos, processos de formação do pensamento abstrato e o desenvolvimento das estruturas matemáticas ${ }^{4}$, desde os primeiros anos na escola. Traz inovações para a didática dessa área do conhecimento, quando propõe concretizações de conceitos matemáticos abstratos, a partir de manipulações de materiais estruturados em jogos, brincadeiras, histórias etc. Seus primeiros livros ${ }^{5}$ : Aprendizado moderno de Matemática e a coleção Primeiros Passos, publicados originalmente na Inglaterra em 1960 e 1966, respectivamente, influenciam até hoje os trabalhos desse campo de pesquisa (FRANÇA, 2012, p. 83).

Seus estudos eram divulgados no Brasil por diferentes grupos de estudos,

3Maiores informações consultar França (2012).

4 Grosso modo, uma estrutura matemática se origina quando se definem certas funções, relações ou coleções de conjuntos, a partir de certos conjuntos básicos de dados ( $A B E$, 1989). Uma estrutura matemática (metaforicamente) é similar a uma escada: não importa a aparência, sua estrutura e a organização dos degraus, são muito parecidas.

5 Obras elaboradas a partir dos trabalhos realizados nos projetos sobre aprendizagem matemática, em Leicester (1958-1959) e em Adelaide (1962-1964). 
principalmente o Grupo de Estudos do Ensino da Matemática (GEEM). Esse grupo foi fundado em 1961, sob a presidência de Oswaldo Sangiorgi, tendo George Springer como colaborador. A maioria dos participantes do grupo dedicou sua vida profissional à divulgação do ideário da Matemática Moderna. Alguns deslocaram seus interesses para a escola primária, produzindo livros didáticos, cursos de formação, documentos oficiais, subsídios para professores etc. Entre eles, estavam Manhucia Perelberg Liberman, Lucília Bechara, Ana Franchi e Maria Amábile Mansutti. A constituição e atuação do GEEM foram de extrema importância para a implantação e divulgação do MMM no Brasil (FRANÇA, 2007).

O Grupo de Estudos sobre o Ensino da Matemática de Porto Alegre (GEEMPA), envolvendo docentes do ensino primário ao superior e liderado pela professora Esther Pillar Grossi, também se destaca na difusão das ideias do MMM no país. No ano de 1972, o grupo fez um convite a Dienes para coordenar a "Jornada de Estudo sobre a Aprendizagem da Matemática", em Porto Alegre. A primeira vez que Dienes veio ao Brasil foi no ano de 1971 por intermédio do GEEM. O GEEMPA organizou dez cursos para os docentes e promoveu "palestras, ciclo de estudos para pais, reuniões de estudo e seminários semanais, publicações para professores" sendo Dienes um dos educadores estrangeiros convidados para auxiliar nesta proposta de capacitação docente (BÚRIGO, 1989, p. 191). Dienes foi a Porto Alegre em várias ocasiões para orientar estudos e experiências realizadas pelo GEEMPA (FISCHER, 2008).

A liderança de Sangiorgi no GEEM e a divulgação do MMM em vários veículos de comunicação, inclusive a televisão, propiciaram que a Matemática Moderna entrasse em muitos lares brasileiros no horário nobre. Veiculava-se que o ensino e aprendizagem da Matemática seriam facilitados sob a perspectiva da Matemática Moderna. A visão da "nova matemática" e suas possibilidades de ensino/aprendizagem aglutinou muitos adeptos. Por todas essas características, Sangiorgi tinha livre acesso a várias esferas e, na maioria das vezes, obtinha condições para executar seus projetos, em relação às reformulações do ensino de Matemática (FRANÇA, 2012).

Naquela época, algumas publicações fizeram circular orientações no que concerne à matemática para ensinar, que estabeleciam mudanças, com vias à uniformização das ações das escolas do recém-criado sistema de ensino. Mas o que seria essa matemática para ensinar, a qual estamos tomando como referência? Segundo Borer (2016), os saberes para ensinar 
configuram-se como saberes profissionais. Eles se desenvolvem por meio da constituição progressiva de um campo disciplinar das ciências da educação. Os saberes a ensinar são aqueles advindos dos campos disciplinares de referência, constituídos pelas disciplinas universitárias. Mais detalhadamente,

O saber a ensinar representado como objeto da docência; e o saber para ensinar caracterizado como ferramenta profissional do professor. O saber a ensinar caracterizado como saber que o professor deve utilizar para a tarefa formativa (por exemplo, referenciado por planos de estudos, programas, manuais etc.); o saber para ensinar como saber que deve ser mobilizado na prática docente (os modos de tratar os saberes a ensinar, as ideias de como os alunos deverão aprender esse saber, os seus modos de aprendizado, as transformações que deverão sofrer os saberes a ensinar etc.) (HOFSTETTER; SCHNEUWLY apud VALENTE, 2017, p. 255-256).

Traremos como referencial os estudos da história da educação e da história cultural, mais especificamente, analisamos em perspectiva histórica a constituição de saberes envolvidos na formação de professores. Tais saberes são considerados sob novas bases conceituais tendo em conta "saberes objetivados", isto é, saberes que se institucionalizam ao longo do tempo, em termos de saberes explícitos, formalizados, transmitidos e incluídos intencionalmente na formação de professores. Além disso, consideramos a expertise como uma ação do especialista em educação em uma instituição aliando saberes da profissão com o da disciplina e esta "participa decisivamente da produção de novos saberes no campo pedagógico". (HOFSTETTER; SCHNEUWLY; FREYMOND, 2017, p. 57). Em suma, definem os saberes a ensinar como aqueles saberes avaliados como objetos do trabalho do professor. Já, os saberes para ensinar, como as ferramentas do seu trabalho.

Hofstetter, Schneuwly e Freymond (2017) consideram a noção de expertise, aquela reconhecida como legítima, atribuída a um ou a vários especialistas. Esses especialistas são distinguidos por seus conhecimentos, atitudes, experiências na análise de uma situação, na avaliação de um fenômeno, na constatação de fatos. Pode-se dizer que são experts porque conhecem bem seu ofício e nele se destacam, aliando saberes da profissão com os da disciplina. Além disso, geralmente, são chamados para resolver problemas práticos por uma instituição pública. De modo geral, a expertise solicitada pelas autoridades de ensino em razão de uma demanda da sociedade para tomada de decisão pode propiciar a produção de novos 
saberes profissionais.

Diante do exposto, busca-se identificar a constituição da expertise de Dienes por meio da análise dos processos de produção, sistematização e objetivação de saberes matemáticos propostos pelo autor em "Un Programme de Mathématique pour Le Niveau Élémentaire", em tempos do MMM, ou ainda evidenciar como Zoltán Dienes, integrante do Centro de Pesquisas Psicomatemáticas, da Université de Sherbrooke, influenciou o ensino da Matemática para o primário por meio do referido programa, o qual teve como coautores Claude Gaulin e Dieter Lunkenbein. O estudo norteia-se pela seguinte questão: Como determinados saberes propostos por Dienes em suas obras divulgadas no Brasil e também em Un Programme de Mathématique pour Le Niveau Élémentaire, em coautoria com Claude Gaulin e Dieter Lunkenbein, se tornaram objetivados na formação de professores e no ensino no Brasil?

Para responder a essa indagação, procuramos, primeiramente, expressar determinadas ideias de Dienes, ressaltando algumas de suas publicações, para, depois, sintetizar as considerações colocadas no Programa, sobre a necessidade de uma nova proposta de ensino de Matemática para as séries iniciais, buscando caracterizar as estratégias utilizadas para anunciar o novo como a alternativa mais adequada e os princípios subjacentes ao mesmo. Nesse sentido, buscamos configurar a abordagem adotada para o ensino de Aritmética em tempos do MMM.

Trazemos ainda para discussão, neste artigo, um recorte da pesquisa que desenvolvemos no Grupo de Pesquisa de História da Educação Matemática (GHEMAT) sobre os saberes para ensinar ${ }^{6}$. Para embasar essa ideia, o grupo, nos últimos dois anos, tem estudado os saberes específicos para a profissão de ensinar e pautado suas pesquisas nas sistematizações pela Equipe de Pesquisa em História das Ciências da Educação $(E R H I S E)^{7}$ da Universidade de Genebra, na Suíça. As pesquisas do grupo suiço revelam uma distinção entre os saberes $a$ ensinar e os saberes para ensinar.

6 Sobre "saberes a ensinar" e "saberes para ensinar" ver: HOFSTETTER, R.; SCHNEUWLY, B. Introduction. In: HOFSTETTER, R. et al. (org.). Savoirs en (trans)formation - Au coeur des professions de l'enseignement et de la formation. Bruxelles: Éditions De Boeck Université, 2009. p. 7-40.

7Para maiores informações sobre o grupo de pesquisa acessar: https://cms.unige.ch/fapse/SSE/erhise. 


\section{Os saberes da profissão}

Por que optar pela pesquisa numa perspectiva dos saberes docentes? Segundo Valente (2017, p. 202), devemos dar voz à ordem do dia: que saberes profissionais devem estar presentes na formação do profissional docente? Acrescentamos que o estudo histórico da constituição desses saberes pode elucidar como foi produzida a representação dos saberes de referência para profissão assim como os experts para defini-los, produzi-los e fazê-los circular por meio de suas obras, cursos etc.

Nas últimas décadas, os documentos produzidos para a escola ou pela escola vêm despertando o interesse de pesquisadores, no âmbito da educação, na tentativa de entender os bastidores do cotidiano escolar. Segundo Valente (2007, p. 36), aos poucos, "novos tipos de fontes vão ganhando importância como ingredientes fundamentais para a escrita do trajeto histórico que o ensino de Matemática seguiu em nosso país". Nesse sentido, esse estudo se interessa também em discutir a expertise do especialista em educação e a produção dos saberes profissionais como categorias para auxiliar nas análises.

É fato que, ao concebermos a expertise de Zoltán Dienes, o tomamos como indivíduo que conhece perfeitamente o ofício docente e nele se destacou, tendo um papel fundamental como organizador do corpo dos Experts das instituições das quais participou, assim como a circulação dos saberes profissionais lá produzidos. Como Hofstetter, Freymond e Schneuwly (2017), consideramos que os especialistas são distinguidos por seus conhecimentos, atitudes, experiências na análise de uma situação, na avaliação de um fenômeno, na constatação de fatos - ou seja, são experts porque conhecem bem seu ofício e nele se destacam, aliando saberes da profissão com as da disciplina, como já destacado anteriormente.

Amparados também nas considerações elaboradas sobre matemática $a$ ensinar - mais diretamente ligada ao campo disciplinar, à matemática - e matemática para ensinar - mais articulada à profissão docente, as ferramentas do professor - aproveitamos para retomar a proposta de investigação sobre os saberes para ensinar produzidos por Dienes, postos a circular no Programa objeto da nossa análise. Nesse sentido, tentamos compreender como se articulam, de um lado, os saberes constitutivos do campo profissional, no qual a referência é a expertise profissional (saberes profissionais ou saberes para ensinar); e, de outro, os saberes 
emanados dos campos disciplinares de referência produzidos pelas disciplinas universitárias (saberes disciplinares, ou saberes concernentes aos saberes a ensinar) (BORER, 2009). Para isso, o referido Programa é analisado na perspectiva da formação dos saberes profissionais, ou seja, o que o expert, um dos autores, produziu em grande medida, a matemática para ensinar.

\section{As ideias de Dienes}

Vários livros de Zoltán Dienes foram publicados no Brasil a partir da década de sessenta do Novecentos. Uma característica marcante nas suas obras é a ênfase dada às contribuições da Psicologia e Pedagogia, presentes em suas propostas, considerando-as, por isto, em constante evolução, a fim de adaptar-se ao desenvolvimento das pesquisas mais recentes naquela época, tanto na Matemática como na Psicologia e, portanto, sujeitas a mudanças significativas.

O autor enfatiza que qualquer proposta de ensino de Matemática deve nortear-se por princípios psicológicos e pedagógicos. Para tal, é exigida uma implantação acompanhada de mudanças também nas maneiras de entender o ensino, a aprendizagem, o papel dos currículos, livros didáticos etc.

Quando uma criança houver efetivamente formado um conceito por meio de suas próprias experiências, terá criado algo que não estava lá antes, e esse algo será elaborado em sua personalidade, no sentido psicológico, do mesmo modo que as substâncias essenciais de seu alimento são elaboradas em seu corpo (DIENES, 1967c, p. 29).

Os trabalhos de Dienes, à luz de Piaget, propunham atividades didáticas que visavam contribuir para a "tomada de consciência da embriologia das noções elementares de Matemática" (LIMA, 1980, p. 52). Dito de outro modo, Dienes buscou concretizar as ideias de Piaget em forma de uma nova metodologia. Produziu uma extensa literatura, demonstrando como ensinar Matemática.

Os princípios de Dienes se fundamentam nas ideias de Jean Piaget sobre o desenvolvimento das estruturas lógicas matemáticas, que dependem da alimentação, complementação e ampliação por meio de adequadas experiências de ensino. A partir dessas condições, a noção de meio é fundamental para compreender as propostas de Dienes. $\mathrm{Na}$ 
medida em que considera a aprendizagem como um processo de adaptação do indivíduo a um meio, condiciona o sucesso da aprendizagem ao poder de "um determinado meio", em gerar situações que exijam do sujeito adaptações para dominar as situações surgidas. Nesse sentido, para ele, o cuidado na construção de um meio profícuo é inerente à aprendizagem.

A metodologia indicada pelo autor consistia basicamente em atividades com jogos realizados em situações artificiais, especialmente construídas, que ilustravam concretamente as estruturas fundamentais da Matemática a ser explorada e o modo como elas se relacionam, originando outras mais complexas, em atividades investigativas, individuais ou em pequenos grupos. "É a partir de um ambiente rico que a criança consegue construir seus conhecimentos, e tomamos como exemplo a aprendizagem da língua materna" (DIENES, 1967b, p. 1). Para Dienes, um trabalho com jogos e materiais manipulativos favoreceria a abstração e o desenvolvimento do raciocínio lógico dos alunos.

O livro de Dienes As seis etapas do processo de aprendizagem em Matemática (1969) era leitura obrigatória nos cursos de capacitação ministrados aos docentes da rede pública de São Paulo. As publicações expedidas pelas Secretarias de Educação do Estado de São Paulo tiveram como base essa obra (FRANÇA, 2012). Esse fato indica a influência do autor nas reformas educacionais que se processaram naquela época.

A didática para o ensino de Matemática, divulgada por Dienes, foi ao encontro das descobertas da Psicologia Genética, concebendo uma escola com métodos ativos. Em seus livros, o autor atribuiu vantagens de seus métodos sobre as metodologias tradicionais, remetendo-se sempre a Piaget. $\mathrm{O}$ anúncio de suas propostas foi acompanhado de exemplos de atividades, geralmente experências malsucedidas do método tradicional, a fim de promover suas proposições como as mais convenientes, condizentes às novas descobertas da Psicologia e da Pedagogia.

Dienes divulgou a representação ${ }^{8}$ de "ensino moderno" como aquele que respeita e contribui para o desenvolvimento das estruturas mentais. Ele ressaltou uma representação de sucesso, que é justificada com o argumento de que, nessa nova metodologia, as atividades

$8 \mathrm{Na}$ articulação das questões, por meio da abordagem da História Cultural, utilizamos os conceitos de representação, apropriação e estratégias postas por Chartier (1991) e Certeau (1982). Chartier (1991, p. 16) define o conceito de representação como: "toda a tradução e interpretação mental de uma realidade exterior percebida. [...], as representações coletivas constroem o próprio mundo social: [...] construções que os grupos fazem sobre suas práticas e que não existem práticas que não sejam representadas". 
eram elaboradas de maneira a permitir maiores interações da criança com o meio, conforme as novas teorias de aprendizagem, respeitando as etapas do desenvolvimento infantil. Seu discurso de convencimento se estruturou a partir de uma análise crítica da atual situação do ensino de Matemática. Construiu as representações de "antigo" e "novo", em um olhar crítico contundentemente sobre os métodos tradicionais, ao mesmo tempo em que anunciou as vantagens do "método novo" proposto por ele.

Quanto à metodologia, Dienes acreditava ser fundamental, para a aprendizagem efetiva, a oferta de situações propícias que alavancassem, concomitantemente, o processo de abstração, de generalização e de transferência, visto que toda aprendizagem equivale a uma maneira de adaptação do organismo ao meio, ou seja, há aprendizagem quando o sujeito consegue modificar seu comportamento em relação ao meio. Dessa forma, processo de aprendizagem significa, ao mesmo tempo, processo de abstração, de generalização e de transferência.

Dienes anunciou suas novas propostas para o ensino a partir da representação de que a natureza generalizada da Matemática era um de seus atributos. A leitura dos prefácios de seus livros da coleção Primeiros Passos em Matemática (1967b) evideciam as representações construídas por ele, para o que considera a "nova" e a "antiga" Matemática.

A matemática não deve ser considerada como um conjunto de técnicas, embora tais técnicas sejam claramente essenciais para a utilização efetiva da Matemática. Esta deve ser vista antes como uma estrutura de relações. O simbolismo formal é somente um meio de comunicar partes da estrutura de uma pessoa para outra (DIENES, 1967a, p. 30)

É fato que, ao propor mudanças, o autor traz a análise do passado em seu auxílio, e divulga a nova didática, contrapondo-a a uma representação de ensino tradicional, construída a partir do diálogo com o passado, num discurso, em grande medida, maniqueísta.Verifica-se, mais claramente, a preocupação de Dienes em eleger sua metodologia como a mais adequada aos novos tempos, trazendo o primeiro capítulo de seu livro Aprendizado Moderno de Matemática (1967a), no qual o autor faz crítica ao passado.

É necessário informar que essa obra é classificada pelos autores das publicações estudadas e por professores entrevistados por França (2012) como a "Bíblia" a ser seguida por 
todos e sempre recomendada aos docentes da rede pública, nos cursos oferecidos. Pelos relatos, tudo indica que, as ideias de Dienes foram divulgadas entre os professores e seguidas pela maioria dos docentes e constituíram-se, para muitos, num informativo de modelos de prática que as Secretarias de Educação esperavam deles, naquele período, em que ocorria uma reformulação curricular.

\section{O Programa de Dienes, Gaulin e Lunkenbein}

O material intitulado Un Programme de Mathématique pour Le Niveau Élémentaire foi traduzido por Anita Rondon Berardinelli e distribuído para os professores no Brasil, por meio do GEEM, em 1969. De acordo com França (2012), o Programa foi considerado documentobase para tentar uniformizar as orientações divulgadas nos cursos para professores da rede pública, tendo em vista a variedade de grupos e instituições encarregadas de produzir material de orientação aos professores das séries iniciais, de como ensinar.

Vários fatores podem ter contribuído para a escolha dessa referência. Entre eles, o prestígio dos autores da tradução do texto de Dienes junto aos professores e o sucesso de sua implementação em classes experimentais, em diversas partes do mundo. Tudo leva a crer que esse programa foi tomado como referência pelo GEEM, e feito circular entre os professores, como uma estratégia para que os princípios da Matemática Moderna fossem apropriados pelos docentes e efetivamente chegassem às escolas nas classes das séries iniciais.

A proposta do Programa, evidenciando os princípios da Matemática Moderna, foi originalmente publicada em 1969, por meio do Centre de Recherches en Psychomathématique, da Universidade de Sherbrooke, Canadá, no Bulletin de l'Association Mathématique du Québec (AMQ) ${ }^{9}$, sendo assinada por Zoltán Dienes, Claude Gaulin e Dieter Lunkenbein. Na apresentação desse Programa, é anunciado que ele foi produto de experiências, coordenadas por Dienes, durante dez anos, em classes experimentais de Sherbrooke, na Austrália. A ação aglutinadora do International Study Group for Mathematics Learning (ISGML) incentivou a colaboração de seus membros e daqueles que almejavam uma nova proposta de ensino e também estavam engajados nas ideias de mudanças, possibilitando 
a experiência com o Programa em várias partes do mundo.

O Programa foi estruturado contendo os seguintes tópicos:

I - Introdução

II - Concepções Subjacentes ao Programa

1 - Concepções matemáticas

1.1 - Conteúdos do Programa

2 - Princípios psicológicos

3 - Princípios pedagógicos

Na Introdução, os autores trazem uma proposta de Programa para a escola elementar, produzindo a necessidade premente de alterações no ensino, com o intuito de abarcar as demandas contemporâneas e superar problemas. A estratégia para convencimento da pertinência da nova proposta assemelha-se ao estilo que Dienes utiliza em outras de suas publicações, ou seja, a crítica ao antigo, indicando suas limitações, e enaltecendo o novo.

No texto, apontam-se que as deficiências dos programas de ensino, naquela época, decorriam por não haver uma articulação entre matemáticos, psicólogos e pedagogos.

A que fatores se deve essa situação atual do ensino de matemática? Sem dúvida, à ignorância de muitos matemáticos sobre os problemas psicológicos inerentes à aprendizagem da matemática. Sem dúvida também, ao conhecimento muito superficial dessa disciplina por numerosos psicólogos (DIENES; GAULIN; LUNKENBEIN, 1969, p. 1).

Reitera-se que as contribuições advindas da Psicologia acarretaram desafios ao ensino e aprendizagem de Matemática. Para superá-los, o programa deveria se coadunar com as necessidades daquele período, de modo realista e aplicável ao desenvolvimento cognitivo das crianças. As assertivas denotavam a representação de um programa, com base psicogenética, expressa pela ênfase que o documento coloca em pontos de vista dos psicólogos.

Após as críticas ao "antigo", os autores se detêm em uma discussão sobre as dificuldades de produzir um programa que contemplasse todas as demandas de uma sociedade em constante evolução. Para eles, essa era um encargo "difícil e exigente" (DIENES; GAULIN; LUNKENBEIN, 1969, p. 17), uma vez que o novo tratamento dado à Matemática envolvia muitas variáveis. Isso significava que um dos fatores mais relevantes para o sucesso escolar, em relação aos saberes matemáticos, seria a necessidade de oferecer à criança 
possibilidades de intervenção, em um meio rico de situações que procurassem atender aos objetivos da Matemática, no estado atual, isto é, adequadas aos recentes estudos, daquela época, sobre o desenvolvimento psicológico.

Tal premissa pressupunha um professor com conhecimento profundo da disciplina, ou seja, com aportes teóricos suficientes para oferecer às crianças um meio profícuo com maiores possibilidades de interação, frente a situações didáticas variadas, com maiores chances para concretizar ideias abstratas, inerentes ao processo de abstração de conceitos matemáticos. Talvez, pelas dificuldades apontadas para elaboração de um programa que considerasse a abordagem estrutural da Matemática, propiciasse a construção de estruturas matemáticas, de acordo com os mais recentes estudos do desenvolvimento psicológico. Os autores sustentavam que a proposta ainda estaria em construção e, por isto, sujeita a mudanças significativas em razão das adaptações exigidas pela divulgação dos resultados das pesquisas recentes, tanto na Matemática como da Psicologia.

$\mathrm{Na}$ Introdução, os autores também enfatizavam a indissociabilidade de alguns princípios psicológicos e pedagógicos em qualquer programa, dito moderno, de Matemática. Desse modo, era necessário que a implantação fosse acompanhada de uma mudança geral, em todos os aspectos envolvidos nos processos de ensino e aprendizagem, nas formas de entender o papel dos currículos, do professor, livros didáticos, do próprio ensino e aprendizagem etc. Ressaltamos que, nesse trecho do texto, há sinais marcantes dos princípios que norteiam a proposta, que revelam uma representação de ensino/aprendizagem atrelada à Matemática, Psicologia e Pedagogia e à fundamentalmente cognitivista, apoiada, de maneira explícita, Epistemologia Genética de Piaget

Outra característica significativa é a incompletude apontada pelos autores, que salientam a contínua construção atribuída por eles, consequência das adaptações exigidas: "Naturalmente nessa perspectiva, a elaboração de um programa moderno, não admite solução única. [...] O programa é moderno e em contínua construção, sendo uma entre várias maneiras adequadas de ensinar matemática" (DIENES; GAULIN; LUNKENBEIN, 1969, p. 1). Nessas afirmações, depreendem-se diferenças em relação à maneira com que Dienes expõe suas propostas metodológicas em outras obras, anunciando-as como sendo a única alternativa adequada. Tudo indica que o lugar de produção do artigo, um periódico com 
distribuição em várias partes do mundo, determinou a mudança.

$\mathrm{Na}$ segunda parte do texto, os autores passam a descrever os pressupostos que conduzem o Programa e os conteúdos a serem abordados. Posteriormente, ilustram como operacionalizar a proposta, descrevendo algumas aplicações práticas realizadas em pesquisas sobre o assunto.

Os autores determinam três eixos norteadores para um programa "moderno": concepções matemáticas, psicológicas e pedagógicas, justificando a adoção de cada um deles, separadamente. Tudo leva a crer que os argumentos e justificativas sobre a ênfase dada à Psicologia e Pedagogia sejam respostas às críticas postas em discussão em encontros internacionais ${ }^{10}$, notadamente, na Conferência de Hamburgo e em um relatório produzido por especialistas, realizada em Hamburgo, em janeiro de 1966. As discussões advinham de experimentos em sala de aula em vários países e o trabalho de pesquisa realizado por psicólogos educacionais, que de acordo com eles, levaram à conclusão de que a capacidade das crianças pequenas de aprender era maior do que se acreditava em tempos passados. Essa nova concepção aglutinou educadores em torno de discussões sobre novas práticas de ensino.

As concepções matemáticas subjacentes ao Programa se constituem o primeiro eixo trazido à discussão. Era descrito um cenário que clamava por reformas nos programas de Matemática e informavam ao leitor algumas condições que possibilitariam ações para requeridas mudanças em classes experimentais. Foram citados os avanços da disciplina, especialmente resultantes dos trabalhos do Grupo Bourbaki ${ }^{11}$, como determinantes para a nova concepção da disciplina, a qual, apoiada na teoria dos conjuntos, tratada como uma estrutura única, enfatizando as estruturas matemáticas, possibilitou melhor visualização de suas aplicações e possíveis relações com outras disciplinas

Essas considerações permitem entender as discussões iniciadas sobre a inadequação

10 Mathematics in Primary Education; International Studies in Education (UNESCO; ISGML, 1966); Mathematics Reform in the Primary School (UNESCO, 1966), entre outros.

110 pseudônimo Nicolas Bourbaki foi adotado por um grupo de matemáticos franceses que escreveu diversos livros versando sobre a matemática avançada moderna, que tiveram sua publicação iniciada em 1935. A proposta do grupo era revisar os fundamentos da matemática se valendo de um maior rigor, utilizando o método axiomático (VITTI, 1998, p. 55). 
dos programas antigos e a necessidade de mudanças. De acordo com os autores, paulatinamente, foram efetivadas ações visando a reforma dos programas de Matemática do ensino secundário. Paralelamente à reforma dos programas do secundário, emerge a necessidade de rever os programas da escola elementar e adequá-los ao plano psicológico. Decorrente das pesquisas dos autores do Programa para a escola elementar, tentando responder a demandas, é sugerido um novo modelo de ensino para a Matemática, destinado às escolas do nível primário de escolarização.

Dienes, Gaulin e Lunkenbein (1969, p. 31) consideravam que o "ensino deve dar ênfase às estruturas matemáticas e lógicas, bem como aos conceitos unificadores de relações, funções (operadores) e morfismos". Segundo eles, era necessário que o ensino de Matemática refletisse as concepções e avanços da disciplina. Nesse sentido, defendem que o Programa:

[...] ultrapassa amplamente os quadros dos programas tradicionais, que se limitavam em geral, aos rudimentos de cálculo e das medidas convencionais. Não obstante, os novos programas não descuidam do aprendizado dos algoritmos práticos e outras aplicações. Ao contrário, acreditamos que, por sua estrutura e metodologia que o acompanha, permite assegurar uma compreensão mais profunda e uma maior aplicabilidade desses algoritmos, em comparação com o ensino tradicional, baseado no treinamento e na memorização (DIENES; GAULIN; LUNKENBEIN, 1969, p. 3).

A citação anterior possibilita-nos fazer inferências no sentido de que o Programa proposto recorria à estratégia de construir uma representação para o "currículo" antigo, de modo a criar a necessidade urgente de alternativas. Revelam embates de representação, no caso as lutas entre propostas de programa, que buscavam se tornar referência. Durante todo o texto, os autores reforçam a representação construída para ensino tradicional e moderno, recorrendo à descrição de exemplos de sucesso para ensino moderno e impertinências e inadequação para ensino tradicional.

Após definirem sua proposta como um Programa moderno, os autores indicam a opção pelas estruturas matemáticas e lógicas, noções unificadoras de relações, funções (operadores) e morfismos. Não obstante a polêmica entre os matemáticos sobre a pertinência do ensino de estruturas matemáticas para crianças, o Programa parte da hipótese que é possível à 
aprendizagem das estruturas matemáticas na escola elementar.

A necessidade de acentuar as estruturas matemáticas, em vez de condicionar as crianças a certos comportamentos em resposta a certos estímulos, foi sublinhada fortemente durante recentes encontros nacionais e internacionais nos quais estavam reunidos matemáticos, psicólogos (DIENES; GAULIN; LUNKENBEIN, 1969, p. 3).

Tudo indica que a discussão, trazida pelos autores, deve ser proveniente das lutas de representação, nos debates sobre reformas nos programas de Matemática na escola elementar, ocorridas em Congressos, como é possível ver nos questionamentos levantados na Conferência de Hamburgo de 1966, que se seguem:

A criança deve aprender estruturas matemáticas tão cedo quanto possível? Em caso afirmativo, por quê? [...] Noções matemáticas simples e básicas deveriam sempre ser introduzidas como preparação para as mais complexas, ou devem essas noções básicas, às vezes, ser introduzidas após as mais complexas? (UNESCO, 1966).

O modo de exploração dos conteúdos matemáticos em uma proposta de ensino para a escola elementar é outro elemento diferencial do Programa. Argumenta-se que, diversamente dos programas antigos, a Matemática deve ser única.

Antigamente a matemática era apresentada como uma justaposição de numerosos assuntos: aritmética, geometria, álgebra, análise etc. Mas, em consequência da reestruturação de que foi objeto desde o início do século, a matemática conquistou uma Unidade (Por quanto tempo?) longamente ambicionada (DIENES; GAULIN; LUNKENBEIN, 1969, p. 5).

Para isso, os conteúdos são elencados, sendo distribuídos em cinco caminhos, como apresentado no Quadro 1, que devem ser explorados paralelamente e com aprofundamento gradativo, interligados, mantendo sua integridade, por meio da presença, em todos eles, de conceitos, estruturas e elementos unificadores, expressos no Caminho 1.

O Quadro 1 dispõe um programa que deveria ser integrado sempre ao Caminho 1 algébrico. Essa proposta se enquadra no aspecto já mencionado de uma matemática para ensinar. Porém, essa proposta exige um profissional que saiba integrar os saberes a ensinar 
com os saberes para ensinar, já que ele deve elaborar atividades que possibilitem aos seus alunos concretizar as ideias abstratas dos conteúdos matemáticos.

Quadro 1 - Conteúdos Matemáticos, distribuídos em caminhos.

\begin{tabular}{|c|c|}
\hline CAMINHOS & CONTEÚDOS MATEMÁTICOS \\
\hline $\begin{array}{l}\text { Caminho } 1 \\
\text { Algébrico }\end{array}$ & $\begin{array}{l}\text { A Noções de conjuntos (conjuntos de elementos, pertinência, complemento, } \\
\text { intersecção, reunião, conjunto de conjuntos, inclusão etc.). Representações por meio } \\
\text { de Diagramas de Venn ou Carroll; } \\
\text { A Relações, operadores, grupos etc.; } \\
\text { A Diagrama de relações de equivalência, de diferença, de ordem etc. Propriedades } \\
\text { das relações binárias, reflexibilidade, transitividade, simetria etc.; } \\
\text { A Operadores (no sentido de aplicação ou função), com casos particulares de } \\
\text { relações. Relação entre operadores e entre cadeias de operadores. Operações } \\
\text { binárias, comutatividade, associatividade, distributividade; } \\
\text { A Concretizações variadas de estruturas matemáticas fundamentais: grupos, } \\
\text { álgebra booleana, anéis, espaços vetoriais, (ou módulos sobre um anel) etc. } \\
\text { Concretizações de isomorfismos e automorfismos de estruturas; } \\
\text { A Introdução à axiomatização. }\end{array}$ \\
\hline $\begin{array}{l}\text { Caminho } 2 \\
\text { Aritmético }\end{array}$ & $\begin{array}{l}\text { A Aprendizagem do número natural a partir de conjuntos. Relações e operadores } \\
\text { numéricos. Relações entre os operadores e cadeias de operadores numéricos; } \\
\text { A Bases de numeração - As quatro operações aritméticas. Comutatividade, } \\
\text { associatividade, distributividade. Generalização para os números racionais positivos; } \\
\text { A Potências, logaritmos, raízes; } \\
\text { A Introdução dos números negativos (a partir dos operadores aditivos ou como } \\
\text { casos particulares de vetores); } \\
\text { A A reta numérica, o plano, e o espaço cartesiano; } \\
\text { A Generalização para polinômios. Formas proposicionais e conjunto solução; } \\
\text { A Concretizações no domínio numérico das estruturas de grupo, anel, corpo; } \\
\text { A Classes resto (módulo n). }\end{array}$ \\
\hline $\begin{array}{c}\text { Caminho } 3 \\
\text { Lógico }\end{array}$ & $\begin{array}{l}\text { A Propriedades (atributos) de objetos ou de conjuntos de objetos. Operações sobre } \\
\text { as propriedades: negação, conjunção, disjunção, implicação, equivalência. } \\
\text { Representação dos maiores conjuntos associados às propriedades, com ajuda de } \\
\text { diagramas de Venn e Carroll, de redes lógicas, de árvores ou cartões perfurados; } \\
\text { A Iniciação à análise combinatória; } \\
\text { A Propriedades compostas (cadeias escritas corretamente). Relações entre } \\
\text { propriedades compostas; } \\
\text { A Regras de inferência; métodos de raciocínio; } \\
\text { A Tabelas de verdade. Quantificador existencial e universal. }\end{array}$ \\
\hline $\begin{array}{l}\text { Caminho } 4 \\
\text { Geométrico }\end{array}$ & $\begin{array}{l}\text { A Figuras geométricas planas e no espaço. Relações entre as figuras geométricas; } \\
\text { A Noções topológicas (fronteiras, regiões, conexidade etc.), projetivas (retas, } \\
\text { intersecção, conexidade etc.), afins (paralelismo, similitude etc.); euclidianas } \\
\text { (distâncias, ângulos etc.); } \\
\text { A Medidas arbitrárias convencionais; } \\
\text { A Operadores sobre figuras geométricas (transformações): simetrias, translações, } \\
\text { rotações, homotetias e suas invariantes. Relações entre operadores e entre cadeias } \\
\text { de operadores geométricos. Simetrias e rotações de poliedros regulares; }\end{array}$ \\
\hline
\end{tabular}




\begin{tabular}{|c|c|}
\hline & A Concretizações de natureza geométrica de grupos matemáticos e de \\
& isomorfismos de grupos. Diagrama de grupos. Relações definidoras num grupo; \\
& A Introdução à axiomatização; \\
& A Transformações geométricas no plano com ajuda de coordenadas; \\
& A Concretizações de módulos (sobre o anel dos inteiros) e de espaços vetoriais. \\
\hline Caminho 5 & \& Conteúdo ainda em estudo. \\
\hline e Estatístico &
\end{tabular}

Fonte: França (2012) adaptado.

Pode-se perceber que a proposta visa um primeiro contato da criança com a Álgebra, seguida pela Aritmética. Esse processo era contrário ao que normalmente era desenvolvido nas escolas, até então, principiando-se pelo ensino da Aritmética, com suas primeiras noções. A Teoria dos Conjuntos deveria subsidiar o desenvolvimento dos conteúdos elementares da Matemática escolar para as séries iniciais.

Os saberes para ensinar se evidenciam nas prescrições em relação aos princípios psicológicos e pedagógicos subjacentes ao programa sugerido. Os autores repetem as justificativas da Introdução, deixando clara a sua representação para o Programa: “[...] apoiados nos trabalhos clássicos de Piaget, admitimos a existência de estágios de desenvolvimento do pensamento. A criança do curso elementar encontra-se no estágio operatório concreto (o intuitivo)" (DIENES; GAULIN; LUNKENBEIN, 1969, p. 8).

É possível obter um maior entendimento das muitas justificativas dos autores quanto aos princípios psicológicos e pedagógicos adotados, quando entrecruzamos outras publicações sobre reforma na escola elementar, publicados pelo Instituto para Educação da UNESCO, nas quais comparecem as lutas de representação de grupos de pesquisadores em Educação Matemática.

As descobertas dos psicólogos tendem a serem muito vagas, muito gerais, ou insuficientemente relacionadas a situações de aprendizagem de matemática para ser de uso e influenciar os rumos do processo de ensino da matemática. [...] os psicólogos não têm o conhecimento matemático necessário para fazer uma contribuição significativa para o ensino da matemática (UNESCO, 1966).

Em defesa da inclusão do material psicológico no Programa, os autores procuram responder as questões, esboçado algumas das razões para o viés adotado. As afirmações circundam no sentido das contribuições mais significativas, provindas de experiências 
realizadas com a participação de matemáticos, psicólogos e professores em exercício e que cada especialista poderia contribuir melhor para a construção de modelos teóricos. Os autores consideram a inclusão de pontos de vista dos psicólogos como um avanço em relação aos antigos programas.

Qualquer que seja o grau de sucesso que os psicólogos têm desfrutado até então, a aprendizagem de matemática certamente traz consigo problemas de natureza psicológica, que necessitam de um exame mais detalhado do que a maioria dos professores estão equipados para oferecer (UNESCO, 1966, p. 10)

Dienes, Gaulin e Lunkenbein (1969) fazem algumas considerações sobre os estudos dos processos cognitivos, mais complexos, que intervêm na aprendizagem de Matemática. Defendem que a aprendizagem dessa área do conhecimento interpõe, para as crianças, vencer etapas de abstrações, ligadas entre si de maneira complexa: "A partir de certo número de situações, constrói-se mentalmente uma propriedade comum a essas situações; depois, em compreensão, a classe correspondente a essa propriedade" (p. 8).

Nessa perspectiva, a aprendizagem se realizaria do simples para o mais complexo. Os elementos da classe formada em compreensão durante o processo de abstração são denominados concretizações múltiplas do conceito ou da estrutura, que consiste em colocar as crianças em situações ricas em possibilidades, numerosas e variadas, de modo a exercitar e, a partir de concretizações, abstrair um conceito. Os autores tentam legitimar o conceito recorrendo a numerosas pesquisas realizadas em diferentes centros afiliados ao SMSG: Serbro, no centro de pesquisas psicomatemáticas, dirigidas por Dienes; em Budapeste, pelo professor Vargas; e no Paedagogische Hochschule Heidelberg, localizado na Alemanha. Posteriormente, os autores também descrevem as fases na abstração de um conceito, definidas por Dienes, inspirado na teoria de Piaget.

Dienes produziu uma teoria sobre os processos de abstração de um conceito matemático. De acordo com ele, esse processo ocorre encadeado e gradualmente, em seis etapas. A novidade do enfoque, nesse caso, é para o estudo com crianças dentro do estágio das operações concretas, período referente à escola elementar. Durante os períodos sensóriomotor, simbólico e das operações concretas, ocorre uma grande elaboração operativa de coordenações de atividades e de estruturas elementares, imprescindíveis para a compreensão 
pela criança dos conceitos matemáticos "elementares" exigidos na escola.

Baseado em estudos psicomatemáticos, desenvolvidos em diferentes meios, Dienes (1967a) estabelece que, nesse período, podem-se distinguir três fases para todo o processo de abstração de um conceito matemático. A cada novo conceito abstraído por meio da exploração de suas relações com outros já adquiridos, originam-se outros, mais complexos.

Na primeira fase do processo, as crianças exploram livremente os materiais e jogos, depois, passam para a segunda fase, em que manipulam e exploram as regras dos jogos, tentando descobrir semelhanças entre elas. Na fase posterior, podem tentar construir isomorfismos que colocam em correspondência os elementos e as propriedades análogas nos diversos jogos. Assim, seria possível chegar progressivamente à abstração de um conceito que pode servir de ponto de partida para novas abstrações.

Para exemplificar: a partir de variados objetos ou figuras quadradas, a criança manipula, explorando seus atributos, até conseguir lhes designar uma propriedade comum, no caso, "ser quadrado". Em seguida, procura formar a classe dos objetos quadrados, em um universo estipulado. Logo, consegue abstrair o conceito de quadrado e, da mesma maneira, constrói os de círculo, triângulo etc. Essas noções já adquiridas funcionam como suporte para abstrair o conceito de forma, depois de figura geométrica etc.

Depois de vencidas as três fases, a criança poderá, posteriormente, completar o ciclo de compreensão de um conceito matemático. Esse processo será ferramenta intuitiva que facilitará a aprendizagem eficaz da Matemática, cada vez mais formal. "O objetivo visado no curso elementar é fazer com que cada aluno adquira uma bagagem de experiências concretas variadas a respeito dessas estruturas a fim de atingir certo grau de generalidade em alguns conceitos fundamentais" (DIENES; GAULIN; LUNKENBEIN, 1969, p. 5).

Tendo em vista a quantidade de questionamentos levantados em Congressos Internacionais, o conceito de concretizações múltiplas é bastante discutido. Um deles se refere à necessidade de maiores estudos sobre a real eficácia do uso de material concreto, que pode desviar a atenção da aprendizagem: "pode atrapalhar o aprendizado, distraindo o aluno dos elementos essenciais exemplificando e detalhando demais os aspectos físicos?" (UNESCO, 1966, p. 11).

Muitas das críticas foram discutidas no Relatório de Hamburgo (UNESCO, 1966). 
Existiam questões sobre o âmbito de sua aplicação:

o princípio das concretizações múltiplas é aplicável para qualquer aluno em qualquer situação de aprendizagem? Onde é que ajuda na abstração de conceitos, e onde atrapalha? Será o princípio da concretização múltipla aplicável em cada situação de aprendizagem? Será que este princípio não pode, por vezes, confundir o aluno?" (UNESCO, ISGML, 1966, p. V).

Parece que, movido pelas polêmicas sobre a pertinência de suas propostas, Dienes dedica atenção especial no texto de proposta do Programa para responder e qualificar suas ideias, por meio de exemplos de sucesso.

Para esclarecer o conceito "colocar a criança em presença de concretizações múltiplas", daremos um exemplo: como serão tratados os conjuntos no curso elementar? Através de múltiplas atividades as crianças se encontrarão em presença de coleções concretas de objetos (blocos, bolinhas, cartões etc.) ou de suas representações gráficas. Será inicialmente sobre esses objetos ou suas representações que elas efetuarão as operações de reunião, intersecção, complementação etc. Assim, graças a uma interação com a realidade material, as crianças abstrairão progressivamente os conceitos de conjunto, pertinência, intersecção etc. (DIENES; GAULIN; LUNKENBEIN, 1969, p. 4).

Dienes, Gaulin e Lunkenbein exemplificam suas ideias, explorando a teoria de conjuntos, para a qual as crianças, em situações concretas, utilizam coleções particulares de objetos, para, em seguida, iniciar o estudo com conjuntos, trabalhando com coleções de quaisquer objetos, contudo, mantendo como referência um conjunto de objetos específicos, com o intuito de possibilitar o uso da intuição, visto que os objetos pertencem a seu universo. Outro ponto a ser destacado, ao longo do texto, é que se verifica a defesa da conveniência da aprendizagem por descoberta. Deve ser salientado que a atividade experimental não é, de forma alguma, unânime em seu apoio à aprendizagem pela descoberta.

\section{Considerações finais}

A Lei 4024/1961 trouxe uma abertura para flexibilizar os programas escolares no país. Nesse sentido, as ideias subjacentes à Matemática Moderna que circularam, naquela época, tiveram as portas abertas para diferentes experimentações em ensino/aprendizagem. Entre os muitos cursos de capacitação de professores, na década de 1970, o GEEM teve um papel 
central nesse processo. No ensino primário, o documento Un Programme de Mathématique pour le Niveau Élémentaire, traduzido e divulgado, foi veiculado em diversas escolas, que, em alguma medida, o adotaram. Alterava-se a organização do ensino de Matemática nas séries iniciais praticada até então.

Em síntese, tudo leva a crer que, a representação sobre o que é um programa adequado de Matemática (como foi proposto para a escola elementar por Dienes, Gaulin e Lunkenbein, e divulgado pelo GEEM) pode ser aquela que deve ser acompanhada de cursos constantes de formação de professores. Além disso, o sucesso da implementação do Programa estaria condicionado a um caminhar conjunto entre matemáticos, psicólogos e pedagogos.

Ensinar Matemática, considerando a nova abordagem estrutural que foi veiculada por meio do Movimento da Matemática Moderna, adequada e aplicável ao desenvolvimento cognitivo das crianças, exigiria um professor com conhecimento profundo da disciplina, ou seja, com aportes teóricos suficientes para oferecer às crianças um meio profícuo com maiores possibilidades de interação, frente a situações didáticas variadas, com maiores chances para concretizar ideias abstratas inerentes ao processo de abstração de conceitos matemáticos. Dessa maneira, a implantação do Programa proposto por Dienes, Gaulin e Lunkenbein deveria ser acompanhada de mudanças em todos os aspectos envolvidos aos processos de ensino e aprendizagem, ou melhor, nas maneiras de entender o ensino, a aprendizagem, o papel dos currículos, do professor, livros didáticos etc. Havia a necessidade de repensar o ensino para crianças, levando para a escola uma abordagem estrutural da disciplina e novas metodologias.

Essas propostas foram efetivadas e ganharam mais espaço no âmbito escolar a partir da publicação de livros didáticos fundamentados nos princípios da Matemática Moderna. Podemos citar como obras destinadas ao ensino primário, que se destacaram naquele cenário, as das autoras Manhuncia Liberman, Lucília Bechara e Anna Franchi (FRANÇA, 2007).

Além da relevância do Programme de Mathématique pour le Niveau Élémentaire e sua repercussão, as obras de Dienes, traduzidas para o português e editadas no Brasil, suas palestras e cursos promovidos no país também têm seu lugar de destaque para a sua caracterização como expert. Essas publicações ocorrem a partir da década de sessenta do Novecentos, sendo relevantes para a disseminação de suas ideias, tendo influência na 
constituição dos saberes profissionais na formação docente e, consequentemente, nas salas de aula do ensino primário, o que também reforça a nossa hipótese inicial. Há que se ressaltar a obra de Dienes Aprendizado Moderno de Matemática (1967), a qual foi tomada como a "Bíblia" durante a difusão do MMM no Brasil, sendo divulgada, adotada e indicada aos professores da rede pública, em cursos que foram ofertados.

A partir de 1970, a coleção Primeiros passos, de Dienes, foi publicada pela EPU, com financiamento do MEC, e supervisão do GEEM, e utilizada como referência para a elaboração de programas de ensino de vários estados brasileiros. É possível dizer que o autor elaborou uma proposta na qual os saberes para ensinar eram enfatizados tendo como suporte as discussões da Pedagogia e Psicologia, fundamentalmente cognitivista, apoiada de maneira explícita na epistemologia genética de Piaget.

Com base em nossas análises, podemos inferir que Dienes foi se profissionalizando no contexto de sua própria história, construindo uma formação específica que foi reconhecida socialmente pelas suas ações, contribuindo na elaboração de saberes para ensinar, saberes que instrumentalizaram a prática de acordo com as concepções modernas de ensino da matemática com indicações técnicas vigentes no período em estudo. Além disso, foi chamado por diversos grupos de estudos brasileiros para resolver um problema prático de como ensinar uma matemática abstrata para crianças.

O estudo evidenciou um saber objetivado para ensinar matemática na escola primária, o que contribuiu para a introdução e elaboração de materiais didáticos em sala de aula, influenciando na formação de professores primários em tal período. Igualmente, a partir do GEEM, de seus livros e da rede de relações produzidas com o MMM, suas propostas reverberaram nos cursos de aperfeiçoamento de professores em diferentes lugares, visto que seus livros foram distribuídos por programas do governo. Em síntese, Dienes pode ser considerado um expert em matemática nas séries iniciais visto que se enquadra em todas as características por nós determinada: um especialista, reconhecido por seus pares, distinguido pelos seus reconhecimentos, atitudes, experiências, sendo constantemente chamado para ocupar cargos em instituições a fim de examinar uma situação, de avaliar um fenômeno, de constatar fatos e produzindo saberes. 


\section{Referências}

ABE, J. M. A noção de estrutura em matemática e física. Estudos Avançados, São Paulo, v. 3, n. 6, maio/ago. 1989.

BORER, V. L. Les savoirs: un enjeu crucial de l'institutionnalisation des formations à l'enseignement. In Hofstetter, R. et al. (org.). Savoirs en (trans)formation: Au cœur des professions de l'enseignement et de la formation. Bruxelles: Éditions de Boeck Université. 2009. p. 41-58.

BORER, V. L. Os saberes: uma questão crucial para a institucionalização da formação de professores. In: HOFSTETTER, R.; VALENTE, W. R. (org.). Saberes em (trans)formação: tema central da formação de professores. São Paulo: Livraria da Física, 2016. p. 173-199.

BÚRIGO, E. Z. Movimento da Matemática Moderna no Brasil: estudo da ação e do pensamento de educadores matemáticos nos anos 60. 1989. 288f. Dissertação (Mestrado em Educação) - Faculdade de Educação, Universidade Federal do Rio Grande do Sul, Porto Alegre, 1989.

CERTEAU, M. de. A escrita da História. Rio de Janeiro: Forense-Universitária, 1982.

CHARTIER, R. A história cultural - Entre práticas e representações. Lisboa: Difel; Rio de Janeiro: Bertrand Brasil, 1991.

DIENES, Z. Aprendizado moderno da Matemática. Rio de Janeiro: Zahar, 1967a.

DIENES, Z. Conjunto, números e potências. São Paulo: Herder, 1967b.

DIENES, Z. A Matemática Moderna no ensino primário. São Paulo: Editora Fundo de Cultura S/A, 1967c.

DIENES, Z. As seis etapas do processo de aprendizagem em Matemática. São Paulo: Herder, 1969.

DIENES, Z; GAULIN, C.; LUNKENBEIN, D. Um programa de matemática para o nível elementar (1ạ parte). Tradução de Anita R. Berardinelli. In: Bulletin de l'A.M.Q. São Paulo: GEEM, 1969. $17 \mathrm{p}$.

FRANÇA, D. M. A. A produção oficial do Movimento da Matemática Moderna para o ensino primário do estado de São Paulo (1960-1980). 2007. 217f. Dissertação (Mestrado em Educação Matemática) - Pontifícia Universidade Católica de São Paulo, São Paulo, 2007. Disponível em: https://repositorio.ufsc.br/handle/123456789/135358. Acesso em: 27 jan. 2017.

FRANÇA, D. M. A. Do primário ao primeiro grau: as transformações da matemática nas orientações das Secretarias de Educação de São Paulo (1961-1979). 2012. 294f. Tese (Doutorado em Educação) - Faculdade de Educação, Universidade de São Paulo, São Paulo, 2012. Disponível em: http://www.teses.usp.br/teses/disponiveis/48/48134/tde-140520 13103937/pt-br.php. Acesso em: 25 abr. 2014.

FISCHER, M. C. B. Formação de professores em tempos de Matemática Moderna: uma proposta de investigação histórica. Revista Diálogo Educacional, v. 8, n. 25, p. 663-678, 
set./dez., 2008.

HOFSTETTER, R., SCHNEUWLY, B.; FREYMOND, M. Penetrar na verdade da escola para ter elementos concretos de sua avaliação: a irresistível institucionalização do expert em educação (século XIX e XX). In: HOFSTETTER, R.; VALENTE, W. R. (org.). Saberes em (trans)formação: tema central da formação de professores. São Paulo: Livraria da Física, 2017. p. 55-112.

LIMA, L. Piaget para principiantes. São Paulo: Summus, 1980.

UNESCO. Mathematics reform in the primary school. Hamburg: UNESCO, 1966. Disponível em: https://unesdoc.unesco.org/ark:/48223/pf0000131548?pos/nSet=2\&queryld=f873664a6f41-4228-a1b3-596a2484fa63. Acesso em: 20 dez. 2018.

UNESCO; ISGML. Mathematics in primary education: learning of mathematics by young children. Hamburg: UNESCO. 1966. Disponível em:

https://unesdoc.unesco.org/ark:/48223/pf0000018427?posInSet $=1$ \&queryld=8176b7b00b74-4f29-8192-7ffc111f6c87. Acesso em: 12 dez. 2018.

VALENTE, W. R. História da Educação Matemática: interrogações metodológicas. REVEMAT Revista Eletrônica de Educação Matemática, v. 2, p. 28-49, 2007.

VALENTE, W. R. A matemática a ensinar e a matemática para ensinar: os saberes para a formação do educador matemático. In: HOFSTETTER, R.; VALENTE, W. R. (org.). Saberes em (trans)formação: tema central da formação de professores. São Paulo: Livraria da Física, 2017. p. 201-228.

VALENTE, W. R. Dos livros didáticos para os cadernos de matemática: a emergência dos saberes profissionais. Zetetiké, v. 25, n.2, p. 254-264, 2017.

VITTI, C. Movimento da Matemática Moderna: memória, vaias e aplausos. 1998. 181f. Tese (Doutorado em Educação) - Programa de Pós-Graduação em Educação. Universidade Metodista de Piracicaba, Piracicaba, 1998.

Recebido em: 28/06/2018

Aprovado em: 15/02/2019 